\title{
DISPUTES OVER INTERMENT AND CREMATION: THE MEDIATION OPTION
}

\section{Yvonne Oldfield*}

\begin{abstract}
Mediation is generally perceived as comparing well to litigation in terms of cost, privacy and speed. Such practical considerations are of as much value to the parties to burial and cremation disputes as they are to the parties in many different types of dispute. Burial and cremation disputes are however particularly difficult and sensitive in nature, often involving complex cultural issues and family conflicts. These characteristic features pose challenges in the mediation context just as they do in litigation.
\end{abstract}

It is argued here that mediation is well suited to addressing these challenges provided mediation style, process and delivery mechanisms are tailored appropriately. The predominant problemsolving model has limitations in meeting cultural and emotional needs, making it essential that a transformative approach informs mediation practice and procedure in relation to burial and cremation disputes.

It is also argued that without their agreement to all aspects of the process, mediation of such disputes may be unsafe for the parties. In addition, where cultural differences or questions of tikanga are at issue, mandatory mediation is of questionable legitimacy. Mediation of burial and cremation disputes, particularly in the New Zealand context, can therefore occur only within a framework that upholds principles of self-determination at every level.

\section{INTRODUCTION}

Third party intervention is not usually required to settle questions about where the bodies of the dead will end up. Certainly the courts are not frequently asked to adjudicate on the subject. ${ }^{1}$ In the relatively rare cases where friends and family of the deceased cannot agree, however, the courts are

* From 2000 until 2011, Yvonne was a Member of the Employment Relations Authority of New Zealand. Since leaving the Authority she has been working and studying at Victoria University of Wellington, where she is responsible for managing student disputes, and has recently completed an LLM. Yvonne would like to thank Dr Grant Morris for assistance with earlier drafts of this article.

1 Takamore v Clarke [2012] NZSC 116, [2013] 2 NZLR 733 at [2] per Elias CJ. 
faced with a delicate and challenging task. As the Chief Justice noted in Takamore v Clarke (Takamore): ${ }^{2}$

$\ldots$ in all societies and in all cultures the disposal of the dead is of great significance to the living and to the religious and cultural traditions to which the deceased and those who care about the deceased belong. Conflict about the disposal and treatment of the dead is inevitably distressing for all because it stirs deep feelings.

If such conflict does end up in litigation (what Josias calls the "default route"3) there is a risk it will become a long-running public spectacle, impeding the grieving process and further damaging strained family relationships. As a result, whatever the outcome at the end of the process, the parties will probably still carry unresolved issues into the future.

This article discusses the potential use of mediation in the resolution of disputes about burial and cremation.

It begins by identifying what is at stake in these complex family and inter-cultural disputes. It outlines the route to be taken if litigation is pursued to resolve these matters, and the legal principles applied in determining them. It suggests that neither the process nor the outcome of the litigation model adequately addresses the cultural and emotional aspects of burial and cremation disputes, but acknowledges that these features pose significant challenges in a mediation context also. The article moves on, therefore, to consider how mediation process and style might be adapted in order to meet these challenges. In the final part, practical consideration is given to the design of a proposed scheme for provision of mediation in burial and cremation disputes.

\section{DISPUTES OVER INTERMENT AND CREMATION}

\section{A Issues}

Some individuals are born into one homogenous community based upon shared culture or religion and stay there all their lives. For many though, especially in a place like New Zealand, notions of community are looser and more changeable. Those who can claim the status of tangata whenua may or may not choose to do so. Immigrants, or their descendants, may or may not identify with the culture of the places they left behind. Some will consider friends or workmates to be their true community, or feel happily and strongly connected to several different cultural groups. Lots of people belong to complex and dynamic families comprising birth, step and adopted parents, siblings and children as well as current and former spouses and partners. The members of these communities and families may no longer live close to each other: increasingly they may be scattered around the country or even the world.

2 At [1] per Elias CJ.

3 Brian L Josias "Burying the Hatchet in Burial Disputes: Applying Alternative Dispute Resolution to Disputes Concerning the Interment of Bodies" (2004) 79 Notre Dame L Rev 1141 at 1154. 
When a person dies, therefore, a relationship with the deceased person may be the only common denominator linking a diverse group of people who have no shared understanding of what should happen next. Burial disputes can involve a number of parties, divergent interests and multiple points of view about what the deceased might have wanted, or about what is right and fitting in the circumstances.

Further compounding the potential for disagreement is the fact that many people are no longer in regular contact with death and dying. The unfamiliarity of death, coupled with natural shock and grief, may leave them poorly equipped to deal with the numerous issues that arise when a loved one dies. Decisions about where, when and how the body is to be disposed of will have to be made in the midst of grief and within a "reasonable time" as required by the Burial and Cremation Act 1964. ${ }^{4}$ As Josias puts it: "Time acts as a secret third party in all of the issues that develop over disposal of bodies. ${ }^{5}$

Conway suggests that burial and cremation disputes can be categorised into conflicts based on sentiment, conflicts based on religious belief and conflicts based on cultural differences. ${ }^{6}$ The parties to such disputes may be driven by grief and emotional ties, by a desire to honour the perceived wishes of the deceased, and by the urge to care for them even in death. Historical resentments may find a new and bitter focus. Old jealousies, power struggles and the sense of past failures may all contribute to a desire to claim, or reclaim, the deceased. ${ }^{7}$

The Takamore case is illustrative of the difficult and painful issues that can arise in such cases. ${ }^{8}$ James Takamore was of Whakatōhea and Tūhoe descent. He and his Pākehā partner Denise Clarke spent twenty years together in Christchurch, raising two children to adulthood, until his sudden death of an aneurysm in 2007. Ms Clarke and her children made plans to bury Mr Takamore at a cemetery near the home they had all shared, but Mr Takamore's mother and other Tūhoe relatives asserted that he should be taken back and buried according to Tūhoe custom in the urupa at Te Upokorehe, their marae. When Ms Clarke would not agree the Tūhoe family members uplifted $\mathrm{Mr}$ Takamore's body and took him to Te Upokorehe.

Ms Clarke sought and won an injunction to prevent his burial, but was too late to stop it. When she and her children applied for a licence to exhume Mr Takamore's body, her in-laws fought her all

4 Burial and Cremation Act 1964, s 46E(1).

5 Josias, above n 3, at 1145.

6 Heather Conway "Dead, but not buried: bodies, burial and family conflicts" (2003) 23 Legal Studies 423 at 428 .

7 Heather Conway and John Stannard "The Honours of Hades: Death, Emotion and the Law of Burial Disputes" (2011) 34 UNSW LJ 860 at 862.

8 Takamore v Clarke, above n 1. 
the way to the Supreme Court. In December 2012, by a majority the Supreme Court ruled that where family and friends cannot agree about what is to happen to the body of a deceased person, the decision rests with the personal representative (executor or administrator of the estate). In this case Ms Clarke was the executor. The matter was remitted to the High Court for orders to deal with the practicalities of exhumation.

On first hearing the outcome, Tūhoe spokesperson Tamati Kruger was reported as saying that the decision "could lead to a standoff with Tūhoe people". ${ }^{9}$ Years of litigation and a Supreme Court decision were not enough to put the dispute between the parties to an end. In early August 2014, local news media reported that protesters blocked Denise Clarke and her children from recovering Mr Takamore's body by means of what they had understood to be an agreed exhumation process. The matter was to be referred back to the High Court again, nearly seven years after Mr Takamore's passing. ${ }^{10}$

The Takamore dispute can be framed in a number of different ways. It can be seen as a family conflict where tensions between in-laws have overwhelmed their ability to resolve disagreements. It can be described as a clash of cultures (as might arise between any two cultural groups in New Zealand) and (distinct from that) it can be construed as a dispute about the place of tikanga in New Zealand's legal system. ${ }^{11}$

So how do we resolve disputes of such complexity?

\section{B The Law}

The common law position is that there is no property in a dead body. ${ }^{12}$ The law does, however, recognise rights to possession arising out of the responsibility for the disposal of the remains of the deceased (the right being incidental to the duty): "The duty to bury is premised on two things: respect for the dead and the interests of the wider community." 13

9 Shane Cowlishaw and Olivia Wannan "Takamore body-snatching case could lead to standoff" The Dominion Post (online edition, Wellington, 19 December 2012).

10 Dana Kinita "The battle over James Takamore" Rotorua Daily Post (online edition, Rotorua, 9 August 2014).

11 Natalie Coates "What does Takamore mean for tikanga? - Takamore v Clarke [2012] NZSC 116" (2013) February Māori LR 14 at 15.

12 Heather Conway "Whose Funeral? Corpses and the Duty to Bury" (2003) 54 N Ir Legal Q 183 at 184.

13 Conway, above n 6, at 426. 
This gives rise to a settled hierarchy of responsibility that has formed the basis for the determination of burial disputes in Britain, Australia and New Zealand. With reference to those cases, Conway notes that: ${ }^{14}$

When confronted with family burial conflicts, courts have resolved them by determining who has the legal right to possession of the corpse and is thus entitled to determine the manner and place of burial.

Judges have consistently rejected arguments based on religious or cultural values, as well as the competing emotions and wishes of the living, as irrelevant in this context.

While this approach has averted the need for judges to make decisions on a subjective basis, it has also meant that the courts have avoided dealing with the underlying issues between the parties, including cultural, emotional and human rights issues. ${ }^{15}$

It is against this background that the Takamore case (the most recent restatement of the law in New Zealand) was decided. The majority decision confirmed the common law position that personal representatives have both a duty and a concomitant right in relation to the disposal of the body of a deceased. When there is no agreement amongst friends and family as to what will happen, the personal representative must decide. The Court expressed the view that: ${ }^{16}$

Having such a rule providing for a decision-maker is both practical and convenient. It will often avoid anyone going to court over their differences because the parties accept or acquiesce in what the personal representative decides. In this way, the rule will often serve the desirability of expedition in a matter which is the occasion of feelings of great grief and loss, while also allowing relevant matters to be addressed

In so doing the decision maker must "take into account different cultural, religious and spiritual practices as well as the views of immediate and wider family". ${ }^{17}$ This is said to mean that "due weight is given by the common law to the tikanga concerning Māori burial practices, where they arise and are brought to the attention of decision-makers". ${ }^{18}$

The personal representative thus bears a significant responsibility. They must adjudicate competing claims, taking into consideration a range of issues, including, if relevant, the place of

14 At 430

15 Kieran McEvoy and Heather Conway "The Dead, the Law, and the Politics of the Past" (2004) 31 JL \& Soc'y 539 at 541.

16 Takamore v Clarke, above n 1, at [153].

17 Takamore v Clarke, above n 1, at [152].

18 Takamore $v$ Clarke, above n 1, at [152]. See also Coates, above n 11. Coates argues that although the Supreme Court decision acknowledged that tikanga was a relevant consideration in the matter, it failed to address the crucial question of "when and how tikanga has the status of law as part of the common law". 
tikanga. Should they have a vested interest (as did Ms Clarke), they must weigh that fairly alongside the interests of other parties. They are given no guidance in all of this.

In the event that the decision of the personal representative is not accepted by all involved, it may be challenged to the High Court where: ${ }^{19}$

... the Court must address the relevant viewpoints and circumstances and decide, making its own

assessment and exercising its own judgment, whether an applicant has established that the decision

taken was not appropriate.

Again, no criteria are provided for the exercise of this judgment. The decision in Takamore therefore suggests that the New Zealand courts must attempt (without much guidance) what has previously been avoided: a subjective evaluation of the competing factors in each case.

Some relief may be at hand in respect of this potential uncertainty. The Law Commission is currently undertaking a first principles review of the Burial and Cremation Act which will look at "rights and responsibilities in relation to the final disposition of deceased persons". ${ }^{20}$

One option for consideration might be to give priority to the wishes of the deceased (where they can be ascertained). This is the prevailing approach in the United States and has been recommended by Conway, ${ }^{21}$ and the Queensland Law Reform Commission, ${ }^{22}$ despite being challenged on the basis that it is grounded in the Western notion of individual rights. It might also find favour here if, as Walker has suggested, both Pākehā and Māori come to consider it appropriate to respect the wishes of the deceased. ${ }^{23}$

Of course, the outcome would remain unclear in cases where it proved impossible to establish what the deceased would have wanted. What then?

19 Takamore v Clarke, above n 1, at [162].

20 Law Commission "Terms of Reference - Review of the Burial and Cremation Act 1964" <www.lawcom.govt.nz>.

21 Heather Conway "Burial Instructions and the Governance of Death" (2012) 12 OUCLJ 59.

22 Queensland Law Reform Commission A Review of the Law in Relation to the Final Disposal of a Dead Body (QLRC R69, 2011)

23 NZPA "'Maori need to accept Pakeha custom'" (30 July 2009) Stuff.co.nz <www.stuff.co.nz〉. 


\section{EVALUATING THE MEDIATION ALTERNATIVE}

\section{A Overview: The Benefits and Disadvantages of Mediation}

Sander, Professor of Law Emeritus at Harvard University, pioneered the idea that litigation works much better in resolving some types of dispute than others ${ }^{24}$ and that the forum should "fit the fuss". ${ }^{25}$ As Josias puts it, speaking of the American context: ${ }^{26}$

Courts are very good at resolving disputes when the issues and the law are clear. The converse is true as well. When the law is unclear ... courts frequently struggle to fashion the appropriate type of relief. The adjudicative model's lack of flexibility and expertise is a serious handicap to the effective resolution of burial disputes.

The implication is that litigation is less well suited to addressing underlying relationship issues, and parties may reach the end of the process with their most deep-seated concerns left unresolved. Judges will arbitrate, when required to do so, between quarrelling family members, but as Chester has put it, "most would agree that the win/lose (zero-sum) results of litigation are not optimal for deciding family conflicts". ${ }^{27}$

Josias sums up the difficulties in using litigation to resolve burial disputes in the following terms: $:^{28}$

Five primary failures of the traditional model emerge. These failures are: inability to deal with matters in

a timely fashion, extraordinary expense, the winner-take-all outcome and consequential damage to close

relationships, failure to deal with the interests of all of the parties involved, and a lack of expertise in

dealing with these issues or lack of flexibility to create innovative solutions.

As we see from the Takamore case, similar failures emerge in the New Zealand context. The issues were complex, the law relating to burial disputes was left unclear and litigation was unable to provide speedy dispute resolution. Just getting to hearing in the High Court took considerable time:

24 Michael L Moffitt "Before the Big Bang: The Making of an ADR Pioneer" (2006) 22 Neg Journal 437 at 437.

25 Frank EA Sander and S Goldberg "Fitting the Forum to the Fuss: A User-Friendly Guide to Selecting an ADR Procedure" (1994) 10 Neg Journal 49.

26 Josias, above $\mathrm{n}$ 3, at 1168.

27 Ronald Chester "Mediation and Jury Trials as Means of Resolving Will Contests" (2001) 1 Pepp Disp Resol LJ 267 at 270 .

28 Josias, above n 3, at 1166. 
Mr Takamore died and was buried in August 2007; the matter was heard in July 2009. ${ }^{29}$ The parties were also subjected to intense media scrutiny of the dispute..$^{30}$

So would mediation work better? Josias suggests that "disputes that involve multiple parties with highly emotional interests and no clear "right" answer recommend themselves most to the use of narrowly tailored dispute resolution techniques". 31

Distinguishing features of mediation as a form of dispute resolution include the potential flexibility it offers in process and outcome and the control the disputants retain over both. These are significant advantages in the sensitive circumstances of burial and cremation disputes.

It may also offer practical benefits (compared to litigation) in relation to privacy, cost and speed. As Genn has pointed out, such expectations often provide the main incentives to mediate: empirical evidence from evaluation of court-based mediation schemes in Canada and the United Kingdom indicates that when parties agree to mediate it may not be because of the perceived strengths of the process but rather "to avoid the anticipated cost, delay and uncertainties of trial". ${ }^{32}$

The potential disadvantages of mediation to the parties are that (because of the need for consent) there is no certainty of settlement. Because there is no public scrutiny of the process (nor, usually, of the outcome) it is also difficult to safeguard procedure or hold mediators to account.

Where mediation becomes a predominant form of dispute resolution, it may also have disadvantages that reach beyond the parties. Because no final decision enters the public domain, there is no prescriptive statement of prevailing views as to what is right - or opportunity to debate that view. While acknowledging "the private value of civil justice ... in the termination of disputes", Genn points out that: ${ }^{33}$

Authoritative judicial determination has a critical public function in common-law systems, creating the framework or the "shadow" in which the settlement of disputes can be achieved ... Even though most disputes settle without the need for trial, a flow of adjudicated cases is necessary to provide guidance on the law and occasionally, to make new leaps.

29 Clarke v Takamore [2010] 2 NZLR 525 (HC).

30 See for example Cowlishaw and Wannan, above n 9; and Kinita, above n 10

31 Josias, above n 3, at 1142 .

32 Hazel Genn "Civil mediation: a measured approach?" (2010) 32 Journal of Social Welfare and Family Law 195 at 199.

33 Hazel Genn "What Is Civil Justice For? Reform ADR, and Access to Justice" (2012) 24 Yale JL \& Human 397 at 398 
Justice Winkelmann, New Zealand's Chief High Court Judge, also considers it is time to "reflect on the role of mediation". ${ }^{34}$ She cautions against the damaging effect of the "anti-litigation narrative" on the civil court system, ${ }^{35}$ arguing that: ${ }^{36}$

... mediation in all its forms is not universally good when viewed from the perspective of the litigant or

the state ... [A]lthough mediation has a place alongside a system of civil justice, it can only be as a complement to that court system ... Adjudication of rights through the courts, whether in a full trial or in

a summary form, does and should continue to remain at the heart of our system of justice.

Such concerns are of importance, especially in any discussion about court-connected mediation (of which more later in this article). Mediation may not be suited to all disputes and it might indeed be worrying if it were to supplant adjudication at the core of our justice system. However, it is probably fair to say that those issues are less critical in the context of such infrequent, subjective and intensely personal disputes as those over burial and cremation. These disputes (as Takamore has shown) are not readily addressed by litigation.

In such a context, mediation may indeed provide the forum which best "fits the fuss". To be effective, however, it must be able to address two key features of these disputes: emotionally charged family conflict and underlying cultural differences.

\section{$B$ The Potential for Transformation}

Mediation has been described as "conflict resolution in a therapeutic key". ${ }^{37}$ Therapeutic jurisprudence is an alternative paradigm of justice fuelled (at least in part) by concerns about the damaging effects of adversarialism. ${ }^{38}$ Its basic premise is that coming into contact with legal processes inevitably has an impact (good or bad) on the mental or physical health of those concerned. The aim of therapeutic jurisprudence is to maximise the positive impact of such processes.

34 Justice Winkelmann "ADR and the Civil Justice System" (paper presented to the Arbitrators' and Mediators' Institute of New Zealand Inc, 6 August 2011) at 1.

35 At 4 .

36 At 2.

37 Ellen Waldman quoted in David Spencer and Michael Brogan Mediation Law and Practice (Cambridge University Press, Melbourne, 2006) at 106

38 Michael King, Arie Freiberg, Becky Batagol and Ross Hyams Non-Adversarial Justice (The Federation Press, Sydney, 2009) at 1. 
Several American commentators have pointed to the value of therapeutic jurisprudence and of mediation in respect of probate disputes, ${ }^{39}$ which of course share much common ground with disputes relating to burials and cremations.

In discussing the benefits of mediation in such cases, Love points out that mediation provides parties with an opportunity to tackle complex emotional issues and interests that cannot be explored within the constraints of litigation, which in this context might include such matters as the need for recognition and respect from other family members or concerns about future family relationships. ${ }^{40}$ She suggests that a "broad approach" to issue identification enables each party to: ${ }^{41}$

... describe and define the conflict as they see fit ... [T] he mediator must capture the issues that the parties describe. Thus the parties are "empowered" by having the real dispute that they are experiencing dealt with as the subject matter of the process.

Love suggests that when family members actively work together to resolve their dispute, they practise skills for use in future conflicts, construct solutions that meet their particular needs and values, and become committed to the outcome: ${ }^{42}$

Mediation has the power to bring parties to a different level of understanding about their underlying situation and about each other, to re-establish family harmony and to resolve ... relationship issues.

If this is to happen however, the style of mediation will be critical.

At one end of the mediation spectrum, evaluative mediation often involves a process of risk assessment, compromise and settlement. ${ }^{43}$ This style of mediation can work well when financial compensation is the main subject of negotiation, and where the issues and law are sufficiently clear for the parties to form some idea of the likely outcome. It is less suited to the resolution of conflict where emotions run high or where the issues are complex and the law unclear - such as burial disputes.

Problem solving or facilitative mediation may be of greater use. This approach entails an exploration of the parties' underlying interests and needs, going beyond the substantive issues to

39 See for example Patricia Monroe Wisnom "Probate Law and Mediation: A Therapeutic Perspective" (1995) 37 Ariz L Rev 1345 at 1353; Dara Greene "Antemortem Probate: A Mediation Model" (1999) 14 Ohio St J on Disp Resol 663.

40 Lela Porter Love "Mediation of Probate Matters: Leaving a Valuable Legacy" (2001) 1 Pepp Disp Resol LJ 255 at 259 .

41 At 262

42 At 256

43 See for example Virginia Goldblatt "Mediation" in Peter Spiller (ed) Dispute Resolution in New Zealand (2nd ed, Oxford University Press, Melbourne, 2007) 69 at 84. 
consider the causes and effects of conflict, including relationship issues. ${ }^{44}$ It can provide a principled mechanism for the resolution of the dispute, and may thereby help preserve a continuing relationship between parties. The focus is still, however, on solving the problem they brought to mediation. Addressing relationship issues is considered primarily as a means to that end.

The "transformative" mediation style reverses this way of looking at the parties' situation. In this approach, advocated by Folger, conflict is not viewed as a problem to be solved: "Disputes that emerge from people's substantive concerns, dissatisfactions and interpersonal or relational tensions can be seen, not as problems, but as opportunities for human growth and transformation." 45

In transformative mediation, the emphasis shifts away from solving the immediate problem and the process itself becomes the focus. Transformative mediation is increasingly being used in situations of complex family conflict, where it has been favourably evaluated. ${ }^{46}$ As Sourdin observes: ${ }^{47}$

In a transformative model, the mediator's role is to foster empowerment and recognition in the parties; this is done by encouraging parties to communicate and make decisions more effectively, subject to their own choices and limits.

There is also support for the argument that a transformative mediation style is essential to, or must inevitably become part of, inter-cultural mediation. Kahane has argued that a "rational" or dispassionate mediation process is culturally located in the same way as a problem-solving or interest-based approach might be. ${ }^{48}$ This point will be revisited later in this article; suffice to say here that Kahane argues that recognition of different approaches to conflict may restore emotion to its "legitimate place" in dispute resolution processes. ${ }^{49} \mathrm{He}$ sees a link between the sort of shifts in thinking required by inter-cultural mediation and the goals of transformative mediation, asking whether there is hope that as a result of the former, "parties will gain a thorough understanding of the other's perspective ... [and] develop a new, shared perspective from which to decide on a just outcome"? $?^{50}$

44 At 81 .

45 Joseph P Folger and Tricia S Jones New Directions in Mediation (Sage Publications, California, 1994) at 15.

46 Tania Sourdin Alternative Dispute Resolution (4th ed, Lawbook Co, Sydney, 2012) at 72.

47 At 72

48 David Kahane "Dispute Resolution and the Politics of Cultural Generalisation" (2003) 19 Neg Journal 5 at 9 .

49 At 16 .

50 At 15. 
Boulle, Goldblatt and Green have also observed: "For Māori coming from a marae-based perspective on life and problem-solving, a transformative model is much more likely to resonate as a process that will work." 51 Transformative mediation, therefore, may be particularly appropriate for burial disputes with their family and inter-cultural characteristics. It may give the parties more chance of addressing psychological and emotional issues, perhaps even providing an opportunity to "repair relationships where they otherwise would have been critically damaged". 52

Criticisms of transformative mediation include the suggestion that it lacks clear objectives and a sound theoretical underpinning. It has also been suggested that by seeking fundamental change in the way people interact, it is effectively (and inappropriately) purporting to "improve the parties' moral character". 53

In response to these criticisms (and the potentially challenging nature of the process) it is essential to make sure that parties freely commit to participation in transformative mediation. Consent is critical if the objective of self-determination is not to be undermined (whatever style or combination of styles is used in mediation). Writing in 2008, Sander bemoaned the lack of attention given to the question: "What is the responsibility of a mediator by way of obtaining meaningful buyin by the disputants at the beginning of the mediation to the method(s) to be employed?"54

Sander identified several factors that will influence how consent should be sought, including: "the nature and circumstances of the case". He noted that parties who are represented, who have previous experience of mediation, who have worked with the same mediator before or who are able to choose their mediator, may not need a great deal of information in order to be able to determine the process used. This is unlikely to be the scenario in a bereavement dispute, however, which may well involve individuals with no prior experience of third-party assistance in dispute resolution. In these cases it will be critical to work with the parties to establish a process that has the express consent of all concerned.

It is probably worth noting, in conclusion, that the mediation of burial and cremation disputes may in practice require a combination of styles. Purists may advocate that any one style should be used exclusively, but practical experience has shown that it is useful for a working mediator to have

51 Laurence Boulle, Virginia Goldblatt and Phillip Green Mediation: Principles, Process, Practice (2nd ed, Lexis Nexis, Wellington, 2008) at 68 .

52 Josias, above $\mathrm{n} 3$, at 1176.

53 Robert A Baruch Bush and Joseph P Folger The Promise of Mediation: The Transformative Approach to Conflict (2nd ed, Jossey-Bass, San Francisco, 2005) at 73. (Bush and Folger acknowledge but reject this construction of the mediator's role in transformative mediation, drawing a distinction between "mediation's potential effects and the principles by which it should be conducted".)

54 Frank Sander "Achieving Meaningful Threshold Consent to Mediator Style(s)" (2008) 14(2) Dispute Resolution Magazine 8 at 9. 
a range of tools available to suit the situation in hand. While the nature of burial and cremation disputes suggests that a transformative style is to be preferred, that could be combined with a problem-solving approach to the extent that the participants feel comfortable with that. As Goldblatt notes: 55

The distinctions between the different models of mediation are by no means clear cut. Frequently any one mediation process can involve a spectrum of approaches. The parties could work towards transforming their relationship with the assistance of a mediator and, once they had succeeded in changing the culture in which the conflict has arisen in quite fundamental ways, they could then conduct the settlement phase of the process ...

\section{The Challenge of Cultural Differences}

As we have seen, burial disputes are essentially family disputes but also, frequently, concern cultural differences. Where they do, as Hooper puts it, cross-cultural issues are more than just a "clip on". 56

Shah-Kazemi explains, in a discussion of family mediation, that culture shapes the way disputants perceive the subject matter, process and options for resolution of a dispute. ${ }^{57}$ She asserts that unless the culture(s) of the disputants informs the style and process of mediation, the benefits of the process (including the potential for parties' self-determination) will be lost. ${ }^{58}$ As she explains: ${ }^{59}$

A few years ago, the suggestion that mediation ... is susceptible to the spectre of cultural hegemony was innovative. Now, however, the idea that the process of mediation must be sensitive to the cultural identities of the disputants is obvious ... [T] he process of ... mediation, does not and cannot be situated in a cultural or normative vacuum: the disputants' view of the world, their cultural identities, their universe of meaning invariably and indelibly shapes the dispute management process.

Particular issues arise in inter-cultural disputes where substantive law and dispute resolution processes may be weighted towards the norms and values of the dominant culture. Kahane says that the dominant culture must address: ${ }^{60}$

55 Goldblatt, above $\mathrm{n} 43$, at 80 .

56 Steven Hooper "Cross Cultural Dispute Resolution" in Peter Spiller (ed) Dispute Resolution in New Zealand (2nd ed, Oxford University Press, Melbourne, 2007) 295 at 295.

57 Sonia Nourin Shah-Kazemi "Cross-Cultural Mediation: A Critical View of the Dynamics of Culture in Family Disputes" (2000) 14 IJLPF 302 at 318.

58 At 321

59 At $302-303$

60 Kahane, above n 48, at 7. 
... challenges to the liberal paradigm of equality and inclusion, which is charged with requiring assimilation to standards that are not themselves neutral but, in fact, represent the perspective of dominant social groups ...

From this critical perspective, culture needs to be taken seriously in debates over justice, in the sense that criteria of fairness are always rooted in particular cultural traditions, rather than in some transcultural definition of human reason, interests, or rights.

According to Kahane, this means that dispute resolution processes must be designed in ways that will "give weight to the range of cultural perspectives in play" and will require the recognition of "asymmetries of power that shape cultural conflicts, as well as obstacles to inter-cultural ... dispute resolution". 61

Kahane asserts that the dominant culture must also re-evaluate ideas about who bears rights and interests. Indeed, he makes the point that the very tendency to frame a dispute in terms of rights and interests (as pre-eminent interest-based and problem-solving models of negotiation and mediation do) is itself culturally determined: ${ }^{62}$

... because interest-based understandings of conflict and conflict resolution reflect a particular cultural background, these ADR methodologies unwittingly favor a dominant cultural perspective, especially if a third-party mediator is of the dominant culture.

A paradigm emphasising the rights of individuals may clash with, or have no relevance to, other cultural frameworks. Tomas and Quince say that this was what happened when the British legal system introduced notions of individual rights that were fundamentally at odds with Māori conceptions of rights: "The imposed new law was a direct threat to collective Māori society ... [Māori] were actively encouraged to put their individual interests first". ${ }^{63}$

Tomas and Quince are speaking here of land ownership issues but the same point is applicable to family disputes. Ruru has argued that (in a Māori context) "it is illogical to separate the individual from his or her relations - be it wider family or the natural environment", ${ }^{64}$ and notes that "current law and policy is grappling with ways in which to recognise and provide for Māori customary family law". 65

61 Kahane, above $\mathrm{n} 48$, at 9 .

62 Kahane, above $\mathrm{n} 48$, at 9 .

63 Nin Tomas and Khylee Quince "Maori Dispute Resolution" in Peter Spiller (ed) Dispute Resolution in New Zealand (2nd ed, Oxford University Press, Melbourne, 2007) 256 at 271

64 Jacinta Ruru "Indigenous Peoples and Family Law: Issues in Aotearoa/New Zealand" (2005) 19 IJLPF 327 at 329 .

65 At 341 . 
Alternative dispute resolution processes, including mediation, have to address similar questions about how to recognise and provide for customary dispute resolution practice, but there is room for optimism that this might be an easier task than that of reconciling different approaches to substantive law. Mediation's inherent flexibility provides an opportunity for the expression of different cultural elements in mediation style and process. Kahane points out that: ${ }^{66}$

Given these critiques of visions of ADR as neutrally mediating interests, some theorists and practitioners of $\mathrm{ADR}$ have attempted to recraft their practice to attend to values at stake in disputes, power differentials between parties; dissonances between the cultural perspectives in play; and mediators' responsibilities to empower parties to the dispute.

Any attempt to mediate burial disputes will need to be firmly grounded in the recognition that the culture (or cultures) of the parties will shape the way they perceive the nature of the dispute, what sort of process they feel comfortable with, who they think should be involved and the options for resolution. Mediators must be aware of the ways in which their own culture influences them, and if part of the dominant culture, they must avoid the trap of perceiving that culture as neutral, invisible or normative.

Where disputants are from different cultures, and that difference is one of the sources of the conflict between them, mediation systems and processes must adapt in response to the values and perceptions of all participants. The next part of the article will briefly consider how that might be achieved in respect of burial disputes involving Māori and Pākehā parties.

\section{TOWARDS A BICULTURAL APPROACH}

Boulle, Goldblatt and Green have said that: ${ }^{67}$

Mediation is often touted as a particularly appropriate process in the context of disputes involving Māori

participants and interests ... The suggestion is that mediation, as a process, is akin to and even draws upon Māori forms of dispute resolution.

Tomas and Quince echo these remarks when asserting that traditional Māori dispute resolution processes "examined the wider context and circumstances before deciding on the best course of action". 68

Although these comments signal the existence of some common ground between Māori and Pākehā upon which a shared model of mediation could be built, it is not possible to predict what that model will look like. As we have seen in the earlier discussion, no inter-cultural dispute resolution

66 Kahane, above n 48, at 9.

67 Boulle, Goldblatt and Green, above n 51, at 67.

68 Tomas and Quince, above n 63, at 273. 
framework can claim legitimacy unless the parties to each dispute retain the ability to determine their own process.

In practice, each dispute will therefore require a preliminary exercise in which the parties work out the process that will suit them. It is useful to identify some questions these parties might want to consider during this preliminary exercise.

Boulle, Goldblatt and Green make several pertinent suggestions. ${ }^{69}$ One relates to the number and range of parties to be involved. This is particularly important in the context of burial disputes, where there may be more than two perspectives on the dispute, and where there may be great benefit in bringing all points of view into the conversation. Those who have not taken polarised positions may well be drawn into crafting a solution, to positive effect. The authors also note that the parties may find it helpful to discuss expectations regarding confidentiality. The parties who attend may consider themselves accountable to many others outside the room and it may not be possible to keep discussions confidential to a relatively small group. Finally, the authors note that the choice of mediator will be critical: the mediator will need to have sufficient standing and knowledge to have the respect of the parties.

MacDuff quotes Hurley as adding to the list: whether co-mediation might be an option; what venue would be suitable; whether food will be provided and how; who can be expected to speak; whether translation will be needed (and if so how that will be arranged), and whether there will be caucusing. ${ }^{70}$

This exercise may, for some, be a challenging process in itself, but will be a crucial precursor to the mediation of substantive matters. Safe exploration of inter-cultural differences, and generation of options for resolution, can occur only within a mediation framework that is contingent upon and respectful of the needs and choices of all parties.

\section{DESIGNING A SYSTEM FOR THE MEDIATION OF BURIAL DISPUTES}

The foregoing evaluation has established the benefits of mediation as a mechanism for the resolution of burial and cremation disputes. This part of the article will consider some practical and structural issues associated with how mediation might be delivered for such disputes. Key considerations here will include the timing of mediation, the extent to which it should be courtconnected, when (if ever) it might be appropriate to compel parties to mediate and how issues of cultural dominance might be addressed. Issues relating to delivery and funding of mediation services will also be touched on briefly.

69 Boulle, Goldblatt and Green, above n 51, at 68-72.

70 Ian MacDuff "Part II: What Would You Do - With a Taniwha at the Table?" (2003) 19 Neg Journal 291 at 293-295. 


\section{A Early Intervention}

Arguably, the trajectory of a bereavement dispute begins even before the loss of the individual whose burial or cremation is in contention. The underlying cultural or other differences between family members may have existed for many years, whether openly expressed or tacitly avoided for the sake of family harmony. Parallels can be drawn with probate disputes, in respect of which some commentators have advocated mediation before the death (at the time the will is being prepared) so that the testator can participate in the mediation and explain his or her wishes in person. ${ }^{71}$

Prudent though such an approach may be, it probably depends on the individual concerned having an unusual level of foresight (or perhaps an estate of significant size). The following discussion will therefore look at the course of a bereavement dispute from the point (after death) where family members have been unable to agree on arrangements, as shaped by the existing legal framework for resolution.

Takamore has confirmed that, in the event that family and friends disagree about funeral and burial arrangements, it falls to the executor or administrator of the estate to decide what must happen. ${ }^{72}$ Any party who disagrees with that decision will be entitled to challenge it to the High Court, which will resolve the matter by balancing a wide range of factors, including the wishes of different family members and friends, any expressed wishes of the deceased, and cultural and religious issues including, where applicable, tikanga. ${ }^{73}$

There are three key points in this process where mediation could be of potential use to disputing family members. The first is at the outset of disagreement, to avoid the need for decision by the executor or administrator. The second is where such a decision is challenged, as an alternative to filing proceedings. The third is after proceedings have been initiated (including where an injunction has been issued.)

There are several arguments to support making mediation available to the parties at the earliest stage. Engaging in mediation before attitudes harden and bitterness becomes entrenched makes sense in many types of dispute, but avoiding delay will be particularly important in respect of burial and cremation disputes where time is a critical factor. Third party assistance could also advance the resolution of matters in cases of intestacy where the parties are waiting on the appointment of an administrator. Finally, third party assistance at the earliest stage could relieve the executor of what may, depending on his or her skills, natural inclination and relationship with the parties, be an onerous burden in arbitrating the dispute.

71 Greene, above n 39.

72 Takamore v Clarke, above n 1, at [144] and [145].

73 Takamore v Clarke, above n 1, at [156]. 
Similar arguments apply at the next point in the process, when the executor or administrator has made a decision that is not accepted by all parties. The positive cost-benefit comparison between mediation and litigation also becomes relevant here. Mediation's low cost and relative speed will, at this stage of the dispute, serve both the parties' and the public interest.

In order for parties to bereavement disputes to be able to use mediation in the early stages of a dispute (before it has reached a court) they would need to know it was available and have some means of gaining access to it. It is not feasible for this to occur through a dedicated mediation service like those for tenancy and employment disputes, as the number of bereavement disputes is just too small.

One approach might be to place services relating to dispute resolution within the scope of Public Trust. ${ }^{74}$ This is the practice in Queensland, where the Public Trust takes on a role in helping resolve burial and cremation disputes at an early stage. ${ }^{75}$ Possible roles for Public Trust might range from provision of mediation itself to maintaining a register of suitably skilled mediators to whom parties might be referred. Were a higher level of service to be provided, consideration could be given to the possibility of some of the cost being borne by the estate.

The third stage at which mediation might be considered is after proceedings have been lodged in the High Court to challenge an executor's decision: essentially court-connected mediation.

\section{B Court-connected Mediation}

The High Court Rules provide for referral to mediation in the following terms: ${ }^{76}$

A Judge may, with the consent of the parties, make an order at any time directing the parties to attempt to settle their dispute by the form of mediation or other alternative dispute resolution (to be specified in the order) agreed to by the parties.

To this extent, court-connected mediation is already available to parties to bereavement disputes.

Is this enough or is there a case for introducing an element of compulsion? And if there is, in what circumstances would it be appropriate? Before looking at these questions in the context of burial disputes it is necessary to consider some of the issues surrounding mandatory mediation generally.

74 The Public Trust website offers general guidance to the recently bereaved and provides a link to relevant resources of the Department of Internal Affairs. Neither site makes reference to the possibility of bereavement disputes or how they might be resolved. See Public Trust "A practical guide for a difficult time" <www.publictrust.co.nz>.

75 Queensland Law Reform Commission, above $\mathrm{n} 22$.

76 High Court Rules, r 7.79(5). 
Opposition to mandatory mediation comes from two directions. On one side, commentators like Genn question the value of forcing parties to mediation. She points out that just a tiny proportion of all disputes end up before the courts and do so precisely because they are not amenable to resolution by other means. ${ }^{77}$ Although she acknowledges that mediation may sometimes assist settlement, she notes that research indicates that: ${ }^{78}$

... facilitation and encouragement together with selective and appropriate pressure are likely to be more

effective and possibly efficient in producing settlements than blanket coercion to mediate.

She fears that mandatory mediation may impede access to justice and even undermine the civil justice system itself. ${ }^{79}$ Speaking of the United Kingdom, she suggests that compulsory mediation and restricted access to civil legal aid comprise a cynical strategy to reduce the burden on the public purse. $^{80}$

Similarly, Justice Winkelmann sees mediation as having value only if it is truly consensual; she is concerned that mediators, who have a vested interest in achieving settlement, may pressure parties to agree. ${ }^{81}$

Opposition to mandatory mediation also comes from those who are mediation's strongest advocates. These opponents do not accept that a distinction can be made between compelling entry into mediation and compelling settlement, as Sander has argued. ${ }^{82}$ They maintain, rather, that its fundamental character is subverted and undermined when it ceases to be a wholly voluntary process.

The common ground between Genn and Winkelmann, on the one hand, and these proponents of mediation on the other, is the perception that if mediation is to fulfill its stated objectives it must not be reduced to an expedient to deal with the problems of cost and delay attendant on the adjudication of disputes. On this analysis, used properly, it should complement adjudication by providing an alternative method of dispute resolution matched to the particular nature of the dispute in question and in accordance with the wishes of the parties.

77 Genn, above n 32, at 199.

78 Genn, above n 33, at 406 .

79 At 411

80 Genn, above n 33, at 196.

81 Winkelmann, above $\mathrm{n} 34$, at 21.

82 Frank EA Sander, H William Allen and Deborah Hensler "Judicial (Mis)use of ADR? A Debate" (1996) 27 U Tol L Rev 885 at 886 . 
Quek recognises the inherent contradiction in forcing parties to enter into a process that is supposedly about empowerment and self-determination, ${ }^{83}$ and accepts that a "compelling reason" is needed to justify any scheme involving an element of coercion. ${ }^{84}$ However, due to what she sees as mediation's undoubted benefits, and the indications that parties who undertake mandatory mediation find it of value, she concludes (with Sander) that: ${ }^{85}$

The need to increase awareness and the usage of mediation services is probably the most compelling reason for introducing mandatory mediation ..

... court-mandated mediation should only be a short-term measure utilized in jurisdictions where mediation is relatively less well developed, and ... this expedient should be lifted as soon as the society's awareness of mediation has reached a satisfactory level.

Meanwhile, Quek has thought about how to apply this "short-term measure" in a way which will address the principal concerns expressed by both sets of opponents of mandatory mediation. She locates existing models of court-connected mediation on a spectrum between those where mediation is completely voluntary and those where the parties have no choice at all about engaging in mediation: 86

1. Categorical or discretionary referral (with no sanctions for refusal);

2. Requirement to attend mediation orientation session or case conference to explore mediation;

3. "Soft" sanctions (making mediation a prerequisite for filing a case or obtaining legal aid; imposing cost sanctions for unreasonable refusal to mediate);

4. Opt-out scheme (compulsory discretionary or categorical mediation with provision to be exempted)

5. "No exemptions" (Categorical or discretionary referral with sanctions for non-compliance)

Quek concludes that: ${ }^{87}$

83 Dorcas Quek "Mandatory Mediation: An Oxymoron? Examining the Feasibility of Implementing a CourtMandated Mediation Program" (2009-2010) 11 Cardozo J Conflict Resol 479 at 481.

84 At 481 .

85 At 484 .

86 At 488. The terms categorical and discretionary are used here by Quek in the same way that Sander uses them: to mean, respectively, referrals in which certain classes of dispute must undergo mediation and referrals in which judges exercise a discretion about which cases will go to mediation: Sander, Allen and Hensler, above $\mathrm{n} 82$, at 885 .

87 Quek, above n 83, at 491. 
... mandatory mediation (falling under categories 1 to 4 of the continuum) does not necessarily contradict or undermine the nature of mediation as a voluntary and consensual process, provided certain conditions are present. Mandatory mediation, as a merely temporary expedient, should remain as an informal process that parties feel comfortable with ... the distinction between coercion into and within the mediation, albeit a fine one, can be maintained if accompanied by appropriate standards of compliance and sanctions.

To address the concern that the parties are losing autonomy, or that a referral might create an element of compulsion to settle, she suggests that the parties retain control over the choice of mediator and mediation arrangements. For the same reason, she suggests allowing exemptions in exceptional circumstances, on the basis of rigorous, clearly expressed criteria that can be applied fairly.

To avoid inefficiencies and heavy costs burdens, she suggests that minimum standards of compliance should be kept simple and specific (essentially, attendance by parties and representatives with authority to settle and sufficient information to engage in the process). She says that sanctions for failing to meet these minimum standards should be minimal, again to counter access to justice issues, and in keeping with the informal and consensual nature of mediation.

Finally she recommends that access to justice concerns must be met by mechanisms to ensure high standards in the delivery of mediation services.

In summary, therefore, Quek justifies an element of compulsion on the basis that it is a necessary short-term expedient to increase awareness and usage of mediation services but acknowledges the need to address the legitimate concerns of those who are opposed to this expedient. She meets this need by incorporating a series of safeguards to preserve the parties' autonomy and control over the process.

I suggest that a similar process could work in New Zealand given certain preconditions. These are discretionary referral, with robust triage, and a low threshold for exemption. The reasons for this are as follows.

Because of the sensitivity of burial and cremation cases, and the vulnerability of disputing parties who have recently lost a loved one, it will not always be reasonable, or even safe, to require them to engage in what can be a very challenging process. The question of compulsion also gives rise to questions of legitimacy in the New Zealand context. Boulle, Goldblatt and Green have observed: ${ }^{88}$

88 Boulle, Goldblatt and Green, above n 51, at 67 
... where mediation takes place in the context of the court system (whether by court referral or in the shadow of the law ... ), it is not, as a process, based upon principles of tikanga or Māori understandings of the nature of a dispute and the process for its resolution.

Other commentators have criticised the "adoption of so-called Māori processes or principles ...within the confines of the overall Westminster derived legal system". ${ }^{89}$ Tomas and Quince quote Jackson as saying: ${ }^{90}$

Protestations about the need for one law for all, or the ability of the common law to rise above its culturally defined origins and become 'bicultural' in the end only serve to maintain the paradigm. They ensure that authority rests where colonisation always intends it to rest-in the institutions established to exercise control over the colonised.

If this assertion were accepted then, given the conclusions reached earlier about what is needed for effective cross-cultural mediation, court-connected mediation conducted under compulsion cannot be "bicultural" and mediation of burial disputes should remain strictly voluntary.

A full discussion of these points is outside the scope of this article but it is suggested that a low threshold for exemption will provide scope for parties who do not accept the legitimacy or appropriateness of mediation (for whatever reason) to reject the process.

Discretionary referral, with robust triage, is important for similar reasons. Boulle, Goldblatt and Green suggest that this should involve a process of matching, screening, and, finally, streaming cases in a direction that will (hopefully) work for the parties concerned. ${ }^{91}$ In "Fitting the Forum to the Fuss", Sander and Goldberg identify what they consider to be the key factors in determining which dispute resolution mechanism is most appropriate for any particular dispute. ${ }^{92}$ These are the goals of the parties, including the relief sought and the value to the parties of preserving their relationship, the complexity and nature of the claim, the potential barriers to resolution (and what dispute resolution mechanism is most likely to overcome them) and finally, what is in the public interest. They argue that the benefits of mediation are such that there is a case to be made for the "[r]ule of presumptive mediation" namely that if mediation "satisfies the parties' goals [it] should, absent compelling indications to the contrary, be the first procedure used".

Genn also considers that good diagnosis is crucial in determining whether mediation should be used, as identified in practice in the Netherlands: ${ }^{93}$

89 Tomas and Quince, above n 63, at 277.

90 Tomas and Quince, above n 63, at 277.

91 Boulle, Goldblatt and Green, above n 51, at 177.

92 Sander and Goldberg, above n 25.

93 Genn, above n 32, at 200-201. 
In her comprehensive analysis of effective court referral to mediation, Judge Machteld Pel argues that successful referral to mediation depends on appropriate analysis of the nature of the dispute or conflict.

She states: "the degree of escalation of a conflict is an important indicator of the applicability and potential effectiveness of mediation", suggesting that the three most important success indicators for achieving a mediated outcome are a willingness to negotiate, space to negotiate and a conflict that has not escalated too far ... in the Netherlands it is accepted that dispute or conflict diagnosis is a necessary step in determining whether a dispute is or is not appropriate for referral to mediation.

In summary, good triage and diagnosis, coupled with scope for exemption where that is warranted, should ensure that mediation will not be undertaken where parties are unable to participate effectively.

\section{CONCLUSION}

Although relatively infrequent, burial and cremation disputes are deeply distressing for all concerned. To litigate such cases has disadvantages in terms of cost, time and loss of privacy. It may not address the existence of multiple parties and interests, and can offer only a limited range of solutions. Instead of healing family relationships, litigation is likely to cause further damage. Finally (and probably because there are so many complexities to consider) the law offers little guidance as to how decisions in burial disputes should be made. Mediation, in contrast, can be cost effective, speedy, private, flexible in both process and outcome, and it provides a way of bringing multiple parties into the conversation. It may offer a viable alternative.

However, because they involve complex family and inter-cultural conflict, burial and cremation disputes pose challenges for the prevailing problem-solving model of mediation. That model may not always address cultural difference adequately, or address emotional issues in ways that enable family relationships to be maintained or restored. This article has argued that for mediation to be effective in addressing burial and cremation disputes, it needs to utilise a transformative model. It has also argued that for inter-cultural disputes in particular, great care must be taken to preserve the principle of self-determination, and to craft a mediation process that has the full and informed consent of all parties. Finally, these conclusions have implications for the design of any courtconnected system for mediation of burial and cremation dispute. It is argued that mandatory mediation is not appropriate in such circumstances. If referrals to mediation were to be made at the discretion of the courts, a low threshold for exemption would be critical to maintain the credibility and legitimacy of the system. 
